\section{Cureus}

\title{
Tracheal Inflammatory Myofibroblastoma: A Rare Tumor of the Trachea
}

\author{
Sonali Gupta ${ }^{1}$, Pradeep Goyal ${ }^{2}$, Yifeng Yang ${ }^{3}$, William Fitzgerald ${ }^{1}$ \\ 1. Internal Medicine, St. Vincent's Medical Center, Bridgeport, USA 2. Radiology, St. Vincent's Medical \\ Center, Bridgeport, USA 3. Internal Medicine, Frank H. Netter MD School of Medicine, North Haven, USA
}

$\square$ Corresponding author: Sonali Gupta, gupta.sonali2706@gmail.com

Disclosures can be found in Additional Information at the end of the article

\section{Abstract}

Inflammatory myofibroblastic tumors (IMTs), also known as inflammatory pseudotumor are rarely reported in the trachea. Although initially considered benign, with the recent evidence of local recurrence after surgical resection, cases of metastatic spread, and advance in cytogenetic analysis, they are now categorized as tumors with malignant potential. Correct histological diagnosis is of utmost importance, as they closely resemble other benign and malignant spindle cell tumors with myofibroblasts predominance. Treatment remains challenging taking into account the location involving the airway. Here, we describe a case of tracheal IMF in an apparently healthy young adult presenting with recurrent hemoptysis.

Categories: Internal Medicine, Oncology, Pulmonology

Keywords: trachea, inflammatory myofibroblastoma, hemoptysis

\section{Introduction}

Inflammatory myofibroblastic tumors (IMTs), also known as inflammatory pseudotumors are rare neoplasms of the respiratory tract. Although they are mostly reported in the lung, tracheal involvement is extremely rare [1]. In the past, they were considered benign; however, with the evidence of local recurrence after surgical resection, cases of metastatic spread, and update on cytogenetic changes, they are categorized as tumors with malignant potential [2]. Correct histological diagnosis is of utmost importance, as they closely resemble other neoplasms such as fibrosarcoma, spindle cell carcinoma or benign conditions such as neurofibroma, pyogenic granuloma, and nodular fasciitis. Treatment remains challenging taking into account the location involving the airway. Here, we describe a case of tracheal IMF in an apparently healthy young adult presenting with recurrent hemoptysis.

Received 03/13/2019

Review began 03/14/2019

Review ended 04/09/2019

Published 04/17/2019

(C) Copyright 2019

Gupta et al. This is an open access article distributed under the terms of the Creative Commons Attribution License CC-BY 3.0., which permits unrestricted use, distribution, and reproduction in any medium, provided the original author and source are credited.

\section{Case Presentation}

A 34-year-old former smoker presented with recurrent episodes of intermittent hemoptysis for three months. He denied associated dyspnea, chest pain, fever, epistaxis, hematuria, blood in stools or ecchymosis. He was not on any antiplatelet or anticoagulant therapy. He had no significant past medical or family history. Initially hemoptysis appeared to subside after a course of antibiotics suggesting an infective etiology. However, hemoptysis recurred and persisted before presentation. Physical examination including nasopharyngeal examination and vital signs were unremarkable. Laboratory investigations including hemoglobin, platelet count, coagulation profile, erythrocyte sedimentation rate, and other biochemical markers were within normal limits. Chest radiograph and electrocardiogram were unremarkable. Bronchoscopy revealed a sessile, polypoidal mass arising from the left posterolateral aspect of the upper trachea with normal appearing but slightly friable mucosa (Figure $1 \mathrm{~A}$ ). Biopsy of the mass was 
taken and sent for histology. The remainder of the trachea and bronchi were normal without lesions or excess secretions. Histopathological examination revealed a storiform pattern of compact spindle-shaped cells mixed with inflammatory cells, mostly lymphocytes and plasma cells (Figures $1 B-1 D$ ). Immunohistochemistry revealed focal positivity for muscle-specific actin, smooth muscle actin, and vimentin (Figures $1 E-1 F$ ). S-100, cytokeratin, cluster of differentiation (CD) 34, CD 117, and myogenin were negative, compatible with tracheal IMF. The patient was then referred for endoscopic resection.

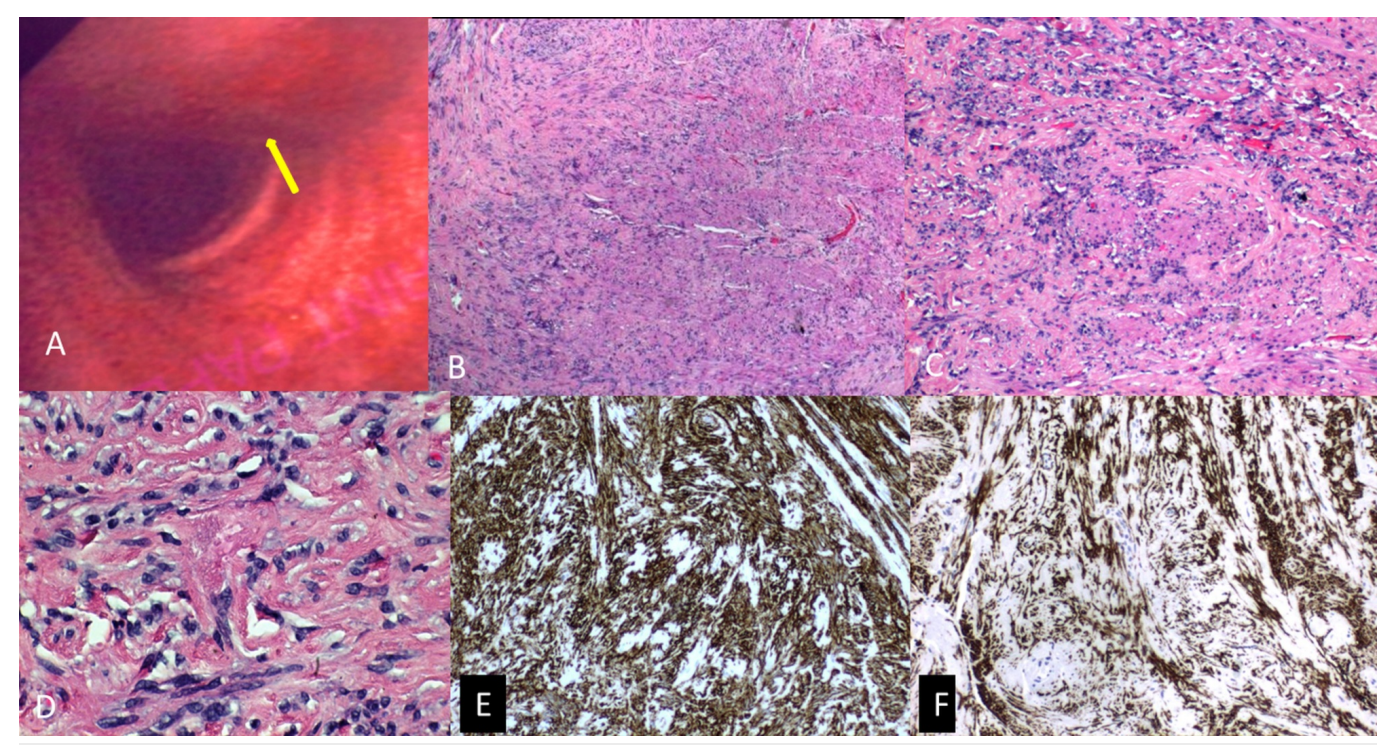

FIGURE 1: (A) Bronchoscopy image demonstrating a sessile, polypoidal mass (yellow arrow) arising from the left posterolateral aspect of the upper trachea with normal appearing but slightly friable mucosa; (B-D) Histopathology specimens: hematoxylin and eosin stain demonstrating storiform pattern with compact spindle cells surrounded by inflammatory cells in the tumor [(B) 40x; (C) 100x; (D) 400x magnification]; (E) Positive immunohistochemical vimentin in the tumor cells; (F) Positive immunohistochemical smooth muscle actin in the tumor cells

\section{Discussion}

Tracheal IMF is very rare, accounting for less than $1 \%$ of all respiratory tract tumors [1]. It has been reported in the pediatric age group; however, it is rarely seen in the adult population [2-3]. It has been reported throughout the body, with lung parenchyma being the most commonly involved site. However, tracheal involvement in adults is extremely rare with a handful of cases reported in the literature [2-3].

Recent reports suggest an association with recurrent translocations involving $2 \mathrm{p} 23$, the anaplastic lymphoma kinase (ALK) gene indicating neoplastic potential [2]. Chromosomal rearrangement involving ALK gene results in the activation of tyrosine kinase receptor, responsible for more aggressive behavior as evident by increased local recurrence after resection and distant metastasis. Trauma, infection, inflammation, and surgery have been 
reported as potential triggers for the development of IMFs. Recently, IMF was recognized as a low-grade mesenchymal malignancy with an excellent prognosis. Modern

immunohistochemistry and fluorescence in situ hybridization can be used to identify the ALK gene, which is reported in up to approximately half of the reported cases and has prognostic significance.

The symptoms are usually nonspecific, and include chronic cough, hemoptysis, pleuritic chest pain, stridor, and post-obstructive pneumonia. Due to its non-specific presentation, it is often missed unless direct laryngoscopy or bronchoscopy is done and the lesion is identified. Grossly, the lesion has been described as nodular, polypoid, or pedunculated [4-6]. They tend to be smooth, fleshy and firm in consistency and the size may range from several millimeters to a few centimeters. To our knowledge, ours is the first reported case of tracheal IMF presenting as recurrent hemoptysis.

Histopathological identification is crucial in diagnosis as it is often misdiagnosed and confused with other neoplasms even by experienced pathologists owing to its low occurrence and a wide variety of presentation. Typically three histologic patterns are recognized [4-6], including spindle or stellate myofibroblasts with abundant inflammatory cells in myxoid stroma or storiform pattern with compact spindle cells surrounded by inflammatory cells or dense collagen with scare cellular pattern. On immunohistochemistry, IMF is typically positive for muscle-specific actin, smooth muscle actin, vimentin, and desmin, while negative for myogenin, cytokeratin, and S100. Differentials include benign and malignant spindle cell tumors with myofibroblasts predominance.

It is commonly managed conservatively with endoscopic laser photocoagulation, cryoablation, or electorcautery $[2,4]$. However, $18 \%-40 \%$ recurrence rate has been reported after conservative management. A few reports suggest radical treatment involving surgical resection of the involved tracheal rings in cases of transmural involvement or radiotherapy for surgically unfit patients [7-8]. Although the prognosis after radical resection is excellent, the procedure is associated with higher morbidity and complication rate. Cerfolio reported a five and 10-year survival rate of $91 \%$ and $77 \%$ respectively, after radical resection of IMFs involvement lung [9]. Fabre et al. also reported an excellent 10-year survival rate after surgical resection [10]. However, the data for tracheal IMFs is limited.

Newer therapies including inhibitors of the tyrosine kinase domain of ALK protein and crizotinib show promising results especially in patients with ALK-translocated IMT [11]. It can be used initially for unresectable tumors to facilitate complete surgical removal or combined with surgery in cases complicated with local recurrence.

\section{Conclusions}

IMF should always be considered in the differential diagnosis for young adults presenting with recurrent hemoptysis. Due to the rarity and scarce literature pertaining to its occurrence, it is often misdiagnosed. It is important for clinicians to be well aware of this entity and to initially consider lesser invasive treatment options including endoscopic resection for endo-luminal lesions, which offers excellent results.

\section{Additional Information}

\section{Disclosures}

Human subjects: Consent was obtained by all participants in this study. IRB Exempt issued approval NA. IRB not required for case report. . Conflicts of interest: In compliance with the ICMJE uniform disclosure form, all authors declare the following: Payment/services info: All 
authors have declared that no financial support was received from any organization for the submitted work. Financial relationships: All authors have declared that they have no financial relationships at present or within the previous three years with any organizations that might have an interest in the submitted work. Other relationships: All authors have declared that there are no other relationships or activities that could appear to have influenced the submitted work.

\section{Acknowledgements}

This case has been presented as poster at annual CHEST conference 2018.

\section{References}

1. Gaissert HA, Grillo HC, Shadmehr MB, Wright CD, Gokhale M, Wain JC, Mathisen DJ: Uncommon primary tracheal tumors . Ann Thorac Surg. 2006, 82:268-272.

10.1016/j.athoracsur.2006.01.065

2. Amir R, Danahey D, Ferrer K, Maffee M: Inflammatory myofibroblastic tumor presenting with tracheal obstruction in a pregnant woman. Am J Otolaryngol. 2002, 23:362-7.

3. Gupta S, Rabold E, Goyal P, Fitzgerald W: Rare cause of recurrent hemoptysis: tracheal myofibroblastoma. Chest. 2018, 154:612A.

4. Jain S, Chopra P, Agarwal A, Gogia S, Basu A: Inflammatory myofibroblastic tumor of trachea . J Bronchology Interv Pulmonol. 2013, 20:80-3. 10.1097/LBR.0b013e31827cd58f

5. Wenig BM, Devaney K, Bisceglia M: Inflammatory myofibroblastic tumor of the larynx. A clinicopathologic study of eight cases simulating a malignant spindle cell neoplasm. Cancer. 1995, 1:2217-29.

6. Özgül MA, Toru Ü, Acat M, et al.: A rare tumor of trachea: inflammatory myofibroblastic tumor diagnosis and endoscopic treatment. Respir Med Case Rep. 2014, 13:57-60. 10.1016/j.rmcr.2014.10.001

7. De Palma A, Loizzi D, Sollitto F, Loizzi M: Surgical treatment of a rare case of tracheal inflammatory pseudotumor in pediatric age. Interact Cardiovasc Thorac Surg. 2009, 9:1035-7. 10.1510/icvts.2009.216499

8. Maier HC, Sommers SC: Recurrent and metastatic pulmonary fibrous histiocytoma/plasma cell granuloma in a child. Cancer. 1987, 60:1073-6.

9. Cerfolio RJ, Allen MS, Nascimento AG, Deschamps C, Trastek VF, Miller DL, Pairolero PC: Inflammatory pseudotumor of the lung. Ann Thorac Surg. 1999, 67:933-936.

10. Fabre D, Fadel E, Singhal S, et al.: Complete resection of pulmonary inflammatory pseudotumors has excellent long term prognosis. J Thorac Cardiovasc Surg. 2009, 137:435440. 10.1016/j.jtcvs.2008.07.009

11. Butrynski JE, D'Adamo DR, Hornick JL, et al.: Crizotinib in ALK-rearranged inflammatory myofibroblastic tumor. N Engl J Med. 2010, 363:1727-1733. 10.1056/NEJMoa1007056 